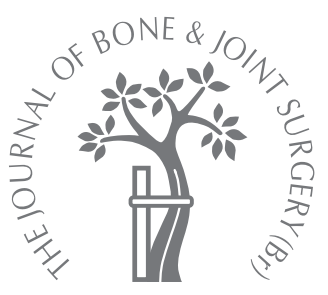

L. Corominas,

K. Z. Masrouha

From University of

Iowa Hospitals and

Clinics, Iowa City,

Iowa, United States

L. Corominas, MD,

Orthopaedic Surgeon

Department of Orthopaedics and Rehabilitation

Hospital Universitario Central de Asturias, Celestino Villamil $\mathrm{s} / \mathrm{n}, 33006$ Oviedo, Asturias,

Spain.

K. Z. Masrouha, MD, Research Fellow

Department of Orthopaedics and Rehabilitation

University of lowa Hospitals and Clinics, 01006 JPP, 200

Hawkins Drive, lowa City, lowa 52242, USA.

Correspondence should be sent to $\mathrm{Dr}$ L. Corominas; e-mail: lauracorominas1979@ hotmail. com

(C)2010 British Editorial Society of Bone and Joint Surgery doi:10.1302/0301-620X.92B9. $24071 \$ 2.00$

$J$ Bone Joint Surg $[\mathrm{Br}]$ 2010;92-B:1300-2

Received 29 November 2009;

Accepted after revision 27 April

2010

\title{
Congenital absence of the posterior arch of the atlas associated with a fracture of the anterior arch
}

\begin{abstract}
Structural defects of the posterior arch of the atlas are rare, and range from clefts of variable location and size to more extensive defects such as complete agenesis. These abnormalities are usually incidental radiological findings. We present a case of a fracture of the anterior arch of the atlas associated with a congenital abnormality of the posterior arch.
\end{abstract}

Congenital partial or complete aplasia of the posterior arch of the atlas is usually an incidental finding ${ }^{1,2}$ during the investigation of neck pain, radiculopathy, swelling in the neck or trauma. Careful differentiation between an acute burst fracture and a congenital defect is essential. A CT scan is helpful in evaluating the integrity of the atlas and differentiating an acute injury from a developmental cleft. ${ }^{3}$

It is unclear as to whether this is a hereditary defect, although two reports have documented the existence of cases involving a mother and son. ${ }^{1,4}$ The incidence between genders is similar and the clinical presentation is variable. Patients are most commonly asymptomatic, although the defect can cause chronic cervical pain, headache and L'Hermitte's sign. ${ }^{5}$

Despite being well-documented, the rarity of the condition leads to errors in diagnosis, and to the lack of confirmation of stability which can result in increased neurological morbidity. ${ }^{6}$ Identifying the transverse atlantoaxial ligament between C1-2 in cases of complete agenesis of the posterior arch is important, since its absence can lead to neurological sequelae, such as atlantoaxial instability or transient quadriparesis. ${ }^{7}$

We present a patient with a previously unreported combination of a fracture of the anterior arch and complete absence of the posterior arch.

\section{Case report}

A previously healthy, right-handed, nine-yearold boy presented with a history of occipital headache for two months after axial compression of his neck while performing somersaults. $\mathrm{He}$ reported that the pain increased with hyperextension of the neck. He had no other symptoms. On examination, there was tenderness and localised swelling at the occipitocervical junction and slight restriction of flexion of the neck. Neurological examination was normal and there were no other musculoskeletal injuries.

Radiographs demonstrated a defect in the posterior arch of the atlas, with no evidence of atlantoaxial instability as assessed by flexion and extension views (Fig. 1). A helical CT scan confirmed complete absence of ossification of the posterior arch of $\mathrm{C} 1$, corresponding with type $\mathrm{E}$ of the Curriano classification. ${ }^{1,8} \mathrm{~A}$ three-dimensional reconstruction gave an additional perspective (Fig. 2). The CT scan also showed appearances suggestive of a vertical fracture through the anterior arch of $\mathrm{C} 1$, with early callus formation. It appeared as a cleft with sclerotic margins. MRI of the cervical spine confirmed the existence of the posterior ligament between $\mathrm{C} 1$ and $\mathrm{C} 2$, providing evidence for the stability of the congenital aplasia (Fig. 3).

The patient was treated conservatively, with non-steroidal anti-inflammatory drugs and a cervical collar for three months. He was referred for physiotherapy and was asked to avoid contact sports and athletic activities. On his last follow-up after 18 months, he was asymptomatic and fully active.

\section{Discussion}

The atlas can be divided anatomically into three parts: the anterior arch, the lateral masses, and the posterior arch. The anterior arch ossifies from one or two centres or, in the absense of a separate centre of ossification, by extension of the lateral masses. Ossification is usually complete by ten years of age. It begins in the posterior arch during the seventh week of intrauterine life, proceeding perichondrally from two centres located in the lateral masses. ${ }^{9}$ The laminae arise from buds in these growth 


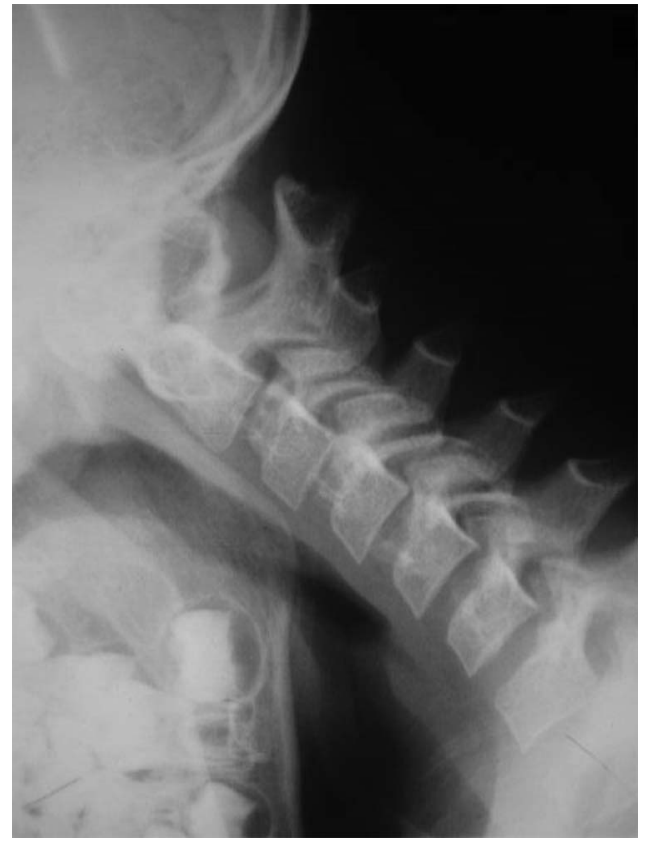

Fig. 1a

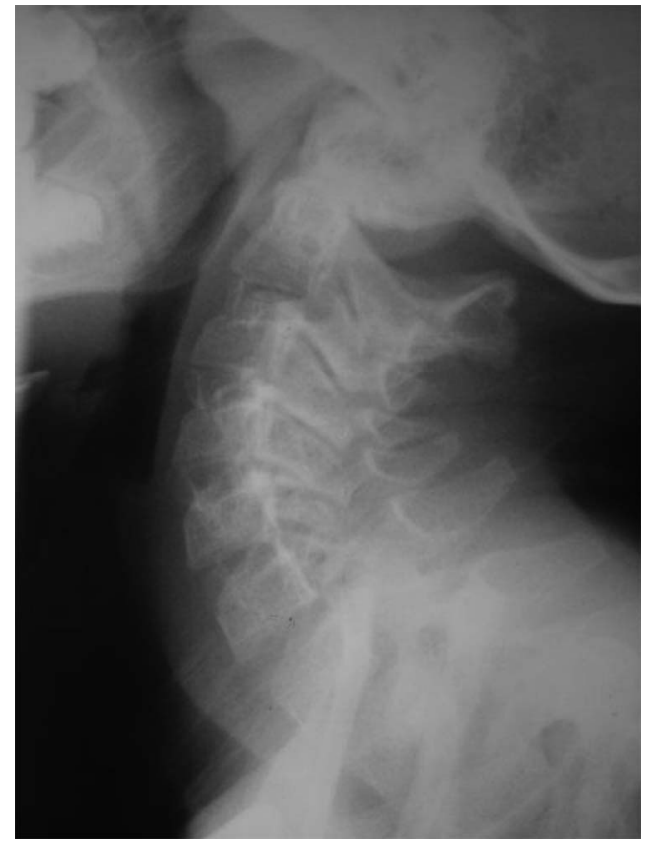

Fig. 1b

Flexion (a) and extension (b) radiographs showing no atlantoaxial instability.

centres and extend dorsally, becoming nearly fused by birth except for several millimetres of cartilage. Complete fusion of the posterior arch is expected between three to five years of age. In about $2 \%$ of the population an additional centre may occur posteriorly in the midline, forming the posterior tubercle of the atlas during the second year of life. ${ }^{10}$

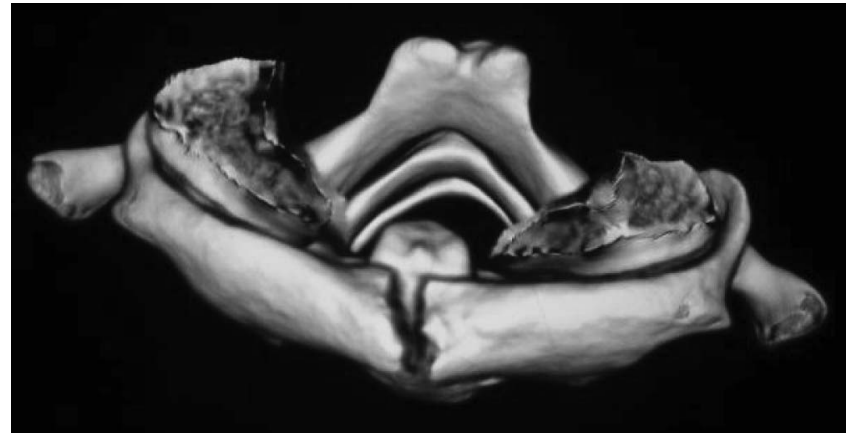

Fig. 2a

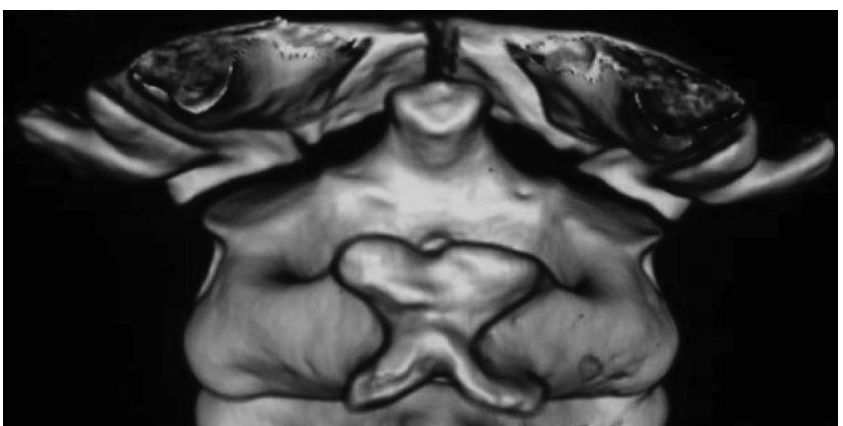

Fig. $2 b$

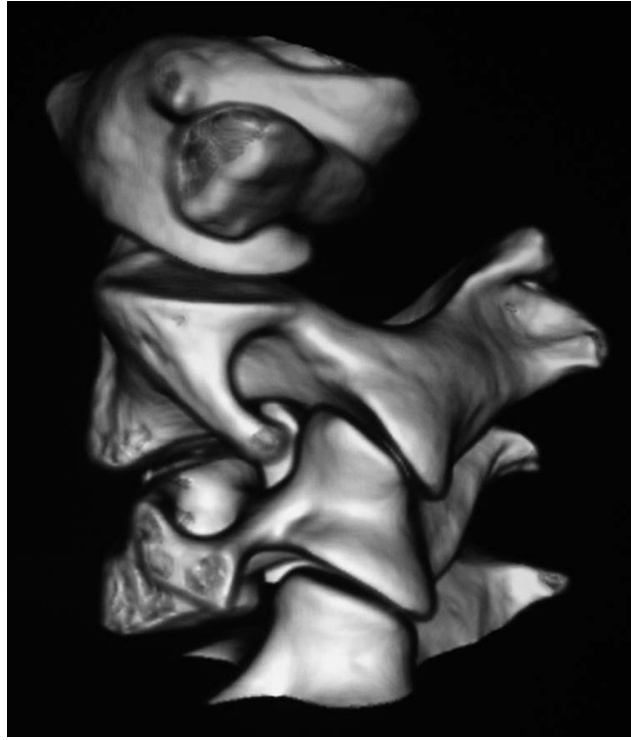

Fig. 2c

Three-dimensional reconstruction of $\mathrm{C} 1$ and $\mathrm{C} 2$ showing absence of the posterior arch and a fracture of the anterior arch of $\mathrm{C} 1$ as seen from a) superior, (b) posterior and (c) lateral views.

At least two different anomalies can develop during ossification, namely median clefts of the posterior arch of C1 and varying degrees of aplasia of the posterior arch. ${ }^{11,12}$ Based on studies conducted by Geipel ${ }^{13}$ and Currarino et $\mathrm{al},{ }^{1}$ these findings have been classified into five different 


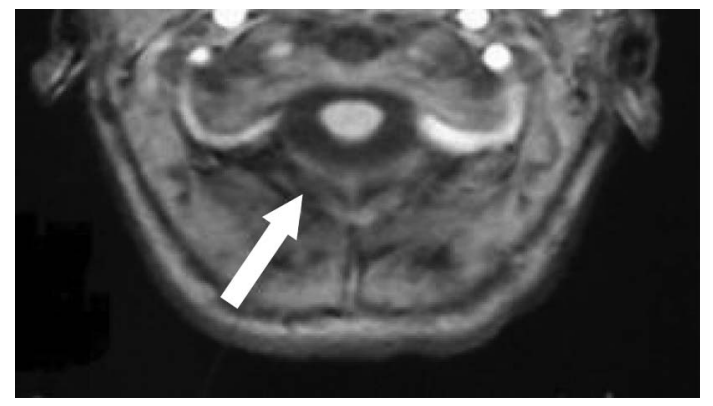

Fig. 3

Cervical MR image showing the intact transverse atlantoaxial ligament (white arrow).

subtypes. In type A there is a median cleft of the posterior arch of C1. The cleft is unilateral in type B and bilateral in type $\mathrm{C}$. In type $\mathrm{D}$ there is absence of the posterior tubercle and in type $\mathrm{E}$ there is total agenesis of the posterior arch. Type A clefts occur in about $4 \%$ of the population and represent $97 \%$ of all posterior defects, whereas types B to $\mathrm{E}$ are reported to occur in $0.69 \%$ of the population. ${ }^{14}$ The presence of an isolated posterior tubercle in types C and D is clinically important because these anomalies can often cause acute neurological deficits such as transient quadriparesis, paraparesis and L'Hermitte's sign, chronic neck pain and headache. ${ }^{15}$ These clinical deficits, have been attributed to anomalies in the cartilaginous development of the posterior arch rather than to disturbances of ossification. ${ }^{16}$

Total or partial aplasia of the posterior atlas arch is rare. Although generally asymptomatic, it may cause neck pain and there is a very rare subset of young patients who develop chronic neurological deficits and atlantoaxial instability. ${ }^{17}$ Defects of the posterior arch commonly occur as isolated abnormalities, yet they may be accompanied by other malformations of the cervical spine, mostly in the atlantoaxial region. A cleft in the midline of the anterior arch of C1 associated with a posterior midline cleft, also known as bipartite atlas, is rare. ${ }^{18}$ This was not observed in our case, although there was a cleft with sclerotic margins causing pain, stiffness and muscle spasm of the neck.

Clefts of the atlas are known to simulate fractures. ${ }^{17,19}$ On imaging, the fractures show irregular edges with associated soft-tissue swelling, while congenital clefts are smooth with an intact cortical wall and have no associated softtissue swelling. CT with three-dimensional reconstruction is extremely helpful in evaluating these spinal anomalies. However, in patients with neurological symptoms, we believe that MRI should be performed to evaluate the spinal cord and adjacent neural structures adequately ${ }^{20}$ and to identify the transverse atlantoaxial ligament between C1-2.

We have presented a case of absence of the posterior arch of the atlas associated with fracture of the anterior arch. Treatment of these anomalies should depend on the presence or absence of atlantoaxial instability, with or without neurological symptoms. MRI should be performed to assess the stability of the upper cervical spine, and whether the agenesis is combined with a vertical fracture of the anterior arch.

No benefits in any form have been received or will be received from a commercial party related directly or indirectly to the subject of this article.

\section{References}

1. Currarino G, Rollins N, Diehl JT. Congenital defects of the posterior arch of the atlas: a case report of seven cases including an affected mother and son. AJNR Am J Neuroradiol 1994;15:249-54.

2. Phan N, Marras C, Midha R, Rowed D. Cervical myelopathy caused by hypoplasia of the atlas: two case reports and review of the literature. Neurosurgery 1998;43:629-33.

3. Kwon JK, Kim MS, Lee GJ. The incidence and clinical implications of congenital defects of atlantal arch. J Korean Neurosurg Soc 2009;46:522-7.

4. Motateanu M, Gudinchet F, Sarraj H, Schnyder P. Case report 665: congenital absence of posterior arch of atlas. Skeletal Radiol 1991;20:231-2.

5. Sagiuchi T, Tachibana S, Sato K, et al. Lhermitte sign during yawning associated with congenital partial aplasia of the posterior arch of the atlas. AJNR Am J Neuroradio/ 2006;27:258-60

6. Thompson GH, Likavec MJ, Archibald I, Rush T. Atlantoaxial rotatory subluxtion, congenital absence of the posterior arch of the atlas, and cerebral palsy: an unusual triad. J Pediatr Orthop 1985;5:232-5

7. Richardson EG, Boone SC, Reid RL. Intermittent quadriparesis associated with a congenital anomaly of the posterior arch of the atlas. J Bone Joint Surg [Am]1975;57-A:853-4.

8. Dalinka MK, Rosenbaum AE, Van Houten F. Congenital absence of the posterior arch of the atlas. Radiology 1972;103:581-3.

9. Schulze PJ, Buurman R. Absence of the posterior arch of the atlas. AJR Am J Roentgenol 1980;134:178-80

10. Childers JC Jr, Wilson FC. Bipartite atlas: review of the literature and report of a case. J Bone Joint Surg [Am] 1971;53-A:578-82.

11. Torriani M, Lourenco JL. Agenesis of the posterior arch of the atlas. Rev Hosp Clin Fac Med Sao Paulo 2002;57:73-6.

12. Klimo P Jr, Blumenthal DT, Couldwell WT. Congenital partial aplasia of the posterior arch of the atlas causing myelopathy: case report and review of the literature. Spine 2003;28:E224-8.

13. Geipel P. Studies on the fissure formation of the atlas and epistropheus: IV. Zentralb/ Allg Pathol 1955;94:19-84.

14. Gangopadhyay S, Aslam M. Posterior arch defects of the atlas: significance in trauma and literature review. Eur J Emerg Med 2003;10:238-40.

15. Sharma A, Gaikwad SB, Deol PS, Mishra NK, Kale SS. Partial aplasia of the posterior arch of the atlas with an isolated posterior arch remnant: findings in three cases. AJNR Am J Neuroradiol 2000;21:1167-71.

16. Kumar R, Kalra SK, Vaid VK, Sahu RN, Mahapatra AK. Craniovertebral junction anomaly with atlas assimilation and reducible atlantoaxial dislocation: a rare constellation of bony abnormalities. Pediatr Neurosurg 2008;44:402-5.

17. Hosalkar HS, Gerardi JA, Shaw BA. Combined asymptomatic congenital anterior and posterior deficiency of the atlas. Pediatr Radiol 2001;31:810-13.

18. Atasoy C, Fitoz S, Karan B, Erden I, Aleyar S. A rare cause of cervical spinal stenosis: posterior arch hypoplasia in a bipartite atlas. Neuroradiology 2002;44:253-5.

19. Suss RA, Zimmerman RD, Leeds NE. Pseudospread of the atlas: false sign of Jefferson fracture in young children. AJR Am J Roentgenol 1983;140:1079-82.

20. Senoglu M, Safavi-Abbasi S, Theodore N, et al. The frequency and clinical significance of congenital defects of the posterior and anterior arch of the atlas. J Neurosurg Spine 2007;7:399-402 